\title{
Enhanced seasonal forecast skill following stratospheric sudden warmings
}

Article

Accepted Version

Sigmond, M., Scinocca, J. F., Kharin, V. V. and Shepherd, T. G. (2013) Enhanced seasonal forecast skill following stratospheric sudden warmings. Nature Geoscience, 6 (2). pp. 98-102. ISSN 1752-0908 doi: https://doi.org/10.1038/NGEO1698 Available at https://centaur.reading.ac.uk/30624/

It is advisable to refer to the publisher's version if you intend to cite from the work. See Guidance on citing.

To link to this article DOI: http://dx.doi.org/10.1038/NGEO1698

Publisher: Nature Publishing

All outputs in CentAUR are protected by Intellectual Property Rights law, including copyright law. Copyright and IPR is retained by the creators or other copyright holders. Terms and conditions for use of this material are defined in the End User Agreement.

\section{www.reading.ac.uk/centaur}

\section{CentAUR}

Central Archive at the University of Reading 
Reading's research outputs online 
1 Enhanced seasonal forecast skill following stratospheric sudden warmings

2

$3 \quad$ M. Sigmond ${ }^{1}$, J. F. Scinocca ${ }^{2}$, V. V. Kharin ${ }^{2}$, T. G. Shepherd ${ }^{1,3}$

4

5

6

7

$8{ }^{1}$ Department of Physics, University of Toronto, Toronto, Ontario, Canada.

$9 \quad{ }^{2}$ Canadian Centre for Climate Modelling and Analysis, Environment Canada, Victoria, British

10 Columbia, Canada

$11{ }^{3}$ Department of Meteorology, University of Reading, Reading, United Kingdom.

12

13

14

15

16 * E-mail: sigmond@atmosp.physics.utoronto.ca

17 Submitted to Nature Geoscience, July 2012 - Revised October 2012 
18 Advances in the field of seasonal forecasting have brought widespread socio-economic benefits.

19 However, seasonal forecast skill in the extratropics is relatively modest ${ }^{1}$, which has prompted the

20 seasonal forecasting community to search for additional sources of predictability ${ }^{2,3}$. For over a

21 decade it has been suggested that the stratosphere can act as a source of enhanced seasonal

22 predictability, as long-lived circulation anomalies in the lower stratosphere following

23 Stratospheric Sudden Warmings are associated with same-signed circulation anomalies in the

24 troposphere for up to two months ${ }^{4,5}$. Here we show that such enhanced predictability can be

25 realized in a dynamical seasonal forecast system, thus opening the door to prediction of a

26 comprehensive suite of parameters of socio-economic relevance. We employ a dynamical

27 forecast system with a good representation of the stratosphere to perform ensemble model

28 forecasts initialized at the onset date of Stratospheric Sudden Warmings. Our model forecasts

29 faithfully reproduce the observed mean tropospheric response in the following months, with

30 enhanced forecast skill of atmospheric circulation patterns, surface temperature over Northern

31 Russia and Eastern Canada, and North Atlantic precipitation. Our results imply that seasonal

32 forecast systems are likely to produce significantly higher forecast skill for certain regions when

33 initialized during Stratospheric Sudden Warmings.

34

36 Skillful seasonal forecasts rely on the predictability of slowly-varying components of the climate

37 system, such as sea surface temperature (SST), sea ice, snow, and soil moisture. Most of the skill

38 that is currently obtained by seasonal forecast systems stems from the predictability of El Niño

39 Southern Oscillation (ENSO) and its remote influences ${ }^{1}$. In general, ENSO's influence declines 
40 with increasing distance from the tropical Pacific Ocean, resulting in relatively smaller forecast

41 skill for the extratropics, especially over Northern Eurasia ${ }^{1,2}$. However, two recent reports ${ }^{2,3}$ have

42 suggested that the maximum seasonal forecast skill has not been achieved, and have identified

43 the stratosphere as an untapped source of enhanced seasonal predictability. This is based on the

44 observation that rapid breakdowns of the westerly flow (or polar vortex) in the polar winter

45 stratosphere (known as Stratospheric Sudden Warmings or SSWs) tend to be followed by a

46 tropospheric circulation pattern that is often described as the negative phase of the Northern

47 Annular Mode (NAM) ${ }^{4}$, with a corresponding signature in surface temperature that is

48 complementary to that of ENSO (i.e. strongest over the Atlantic sector and Northern Eurasia,

49 where the ENSO impact is modest) ${ }^{5}$. However, SSWs are highly nonlinear events that are only

50 predictable a week or two in advance ${ }^{6,7}$. Consequently, the enhanced seasonal predictability

51 coming from the stratosphere is likely to be conditional (i.e., only after a SSW has occurred).

53 Previous studies of enhanced seasonal predictability associated with SSWs are mainly based on 54 simple statistical models ${ }^{8-11}$. Seasonal forecast systems based on dynamical models are able to 55 capture the average tropospheric state following SSWs to some extent ${ }^{12}$, but it is not evident that 56 this is associated with a detectable increase in forecast skill of surface weather ${ }^{13}$. Here we 57 demonstrate that a dynamical forecast system initialized at the time of a SSW is able to predict

58 the mean tropospheric circulation response in the following months. We also show that the

59 forecast skill of socio-economically relevant variables such as surface temperature and 60 precipitation is significantly enhanced relative to the forecast skill in a set of unconditional 61 forecasts (i.e. control forecasts that are not explicitly initialized during SSWs). 
63 The dynamical forecast system in this study employs the Canadian Middle Atmosphere Model

$64(\mathrm{CMAM})^{14}$. Retrospective forecasts (also known as hindcasts) are initialized at $20 \mathrm{SSW}$ dates

65 between 1970 and 2009 (hereafter referred to as the SSW forecasts), each consisting of 10

66 ensemble members. In all model forecasts, SST anomalies that occur at initialization time are

67 thereafter relaxed to climatology as described in the Methods section. This allows us to exclude

68 predictability that may arise from SSTs (e.g., related to the ENSO phenomenon), thus isolating

69 predictability that stems from atmospheric and associated land initializations. We focus on the

70 ensemble mean forecast averaged over the 16-60 days after the SSWs. Forecast anomalies are

71 defined as differences relative to the climatology of the unforced (freely running) model (see the

72 Methods section).

74 The model prediction of the anomalous tropospheric state following SSWs agrees very well with 75 observations (Fig. 1; see also Supplementary Fig. S1). Figs. 1a and 1c (contours) show that 76 averaged over all 20 SSW cases, the observed Sea Level Pressure (SLP) pattern is characterized 77 by a dipole with anomalously high SLP at high latitudes and anomalously low SLP at mid-

78 latitudes. This pattern is often described as a negative NAM pattern. It is well reproduced by the 79 model (Figs. 1b and 1d), except that the centre of anomalously low SLP in the North Atlantic is 80 shifted east relative to that in the observations. The negative NAM pattern is associated with a 81 near-surface easterly wind anomaly at NH mid-latitudes (not shown), which results in increased 82 (decreased) advection of relatively warm ocean air to Eastern Canada (Northern Russia) ${ }^{15}$. The 83 resulting warm anomaly over Eastern Canada and cold anomaly over Northern Russia (Fig. 1a) 
84 is again well captured by the model (Fig. 1b). The negative NAM pattern is also consistent with an equatorward shift of the storm track (not shown), which is associated with decreased precipitation (PCP) over the high-latitude Atlantic, and increased PCP over the mid-latitude Atlantic (Fig. 1c). This feature is again well reproduced by the model (Fig. 1d), except that, consistent with the SLP, the centre of anomalously high PCP in the mid-latitude North Atlantic is shifted east relative to that in the observations.

The implications for forecast skill can be understood by considering Fig. 2a. It shows a scatter plot of the observed versus forecast NAM index at $1000 \mathrm{hPa}$, where each point represents one (ensemble mean) model forecast initialized at a particular SSW date. Most points are located in the lower left quadrant, reflecting the fact that on average both the observed and modeled surface NAM following the SSWs is negative. The average horizontal location (represented by the vertical dashed line) is the mean observed value (-0.44). The horizontal error bar shows that the observed mean surface NAM response is statistically significant at the $95 \%$ confidence level. The average modeled surface NAM, which is the average vertical location of the points, is somewhat larger (-0.74) and also statistically significant. The correlation between observed and modeled surface NAM (hereafter referred to as the Correlation Skill Score (CSS) or simply 'forecast skill') is substantial ( $\mathrm{r}=0.55)$ and statistically significant at the $99 \%$ confidence level (see also Fig. 4a), which is a reflection of the tendency of the points in the scatter plot to be shifted towards the lower left quadrant. Thus, we find that our model has a significant skill in forecasting the surface circulation for a lead time of 16-60 days. 
106 Some of the skill in the SSW forecasts may, in principle, also stem from predictability of slowly

107 varying boundary conditions such as soil moisture (as noted above, the model forecasts are

108 designed to exclude SST effects on predictability). To quantify such skill, we performed a

109 control set of forecasts initialized at the same calendar dates as the SSWs, but in the year

110 preceding and the year following the SSWs. The results are plotted in Fig. 2b. We find a similar

111 spread in the observed and modeled surface NAM index as in the SSW forecasts, but instead of

112 being shifted towards a particular quadrant, the cloud of points is centered near the origin. The

113 near-zero (-0.01) CSS for the surface NAM demonstrates that the unconditional control forecasts

114 do not contain any forecast skill for the surface circulation for a lead time of 16-60 days,

115 demonstrating that the skill in the SSW forecasts does come from the SSWs themselves. Note

116 that the similar spread in the cloud of points in Figures $2 \mathrm{a}$ and $2 \mathrm{~b}$ suggests that the inherent

117 predictability of the surface NAM is not enhanced after SSWs, but instead that the increased

118 correlation skill score in the SSW forecasts is largely due to the shift in the mean NAM towards 119 negative values.

121 The vertical profile of the mean NAM index following the SSWs is well captured by the model

122 forecasts (Fig. 3a). The model slightly overestimates the mean NAM response near the surface,

123 but correctly captures the vertical structure which maximizes in the lower stratosphere and

124 exhibits a minimum in the middle troposphere. The corresponding forecast skill is shown in Fig.

125 3b. Consistent with Fig. 2, it shows that near the surface the forecast skill is substantial and

126 significant for the SSW forecasts, and near-zero and not significant for the control forecasts.

127 Except for the mid to upper troposphere, forecast skill of the NAM following SSWs is 
128 substantial, statistically significant, and significantly larger than in forecasts that are not 129 constrained to be initialized during SSWs.

131 The influence of SSWs on forecast skill for the NAM index and for Northern Hemisphere

132 surface variables is summarized in Fig. 4. The statistical significance of the difference between

133 the CSS in the SSW and control forecasts is labeled by p-values in this figure, which represent

134 the confidence level at which enhanced forecast skill can be associated with SSWs and which are

135 determined by bootstrapping. This level exceeds $99 \%(\mathrm{p}<0.01)$ for the NAM at 100 and 1000

$136 \mathrm{hPa}$ (Fig. 4a), and is 98\% for the North Atlantic Oscillation (NAO) (which is the local Atlantic

137 manifestation of the surface NAM and is defined here as the SLP difference between Iceland and 138 the Azores) (Fig. 4b). For SLP, Surface Temperature (ST) and PCP, forecast skill averaged over $13920-90^{\circ} \mathrm{N}$ (left bars in Figs. 4b-d) is statistically significant in the SSW forecasts, and enhanced 140 relative to that in the control forecasts. However, this enhancement is only statistically

141 significant for SLP ( $\mathrm{p}=0.04)$. Focusing on localized regions, significant skill enhancement can be 142 detected for ST in Northern Russia and Eastern Canada (Fig. 4c) and for the PCP gradient over 143 the Northern Atlantic (Fig. 4d).

145 For more than a decade it has been suggested that the stratosphere can act as a source of seasonal 146 predictability. The results in this paper confirm that such predictability can be realized in 147 dynamical forecast systems. A requirement for the predictability to be realized is a model that 148 realistically simulates the tropospheric response to SSWs. Even though current seasonal forecast 
149 systems (which generally have a poorly represented stratosphere) capture this response with

150 some credibility ${ }^{12}$, it has been suggested that the response is more realistic in models with a well-

151 represented stratosphere ${ }^{16}$ such as the model employed here. Also, as SSWs themselves are

152 better predicted with a longer lead time in such models ${ }^{7}$ it may be possible to elevate seasonal

153 forecast skill by raising the model lid and increasing vertical resolution in the stratosphere ${ }^{2,17}$.

155 In assessing the practical implications of these results it must be noted that the enhanced

156 predictability is highly conditional and contingent upon the occurrence of SSWs, which occur on

157 average in six out of ten winters. Although the seasonal predictability associated with ENSO is

158 also conditional, there are two important differences: 1) SSWs are inherently less predictable

159 than ENSO giving a shorter lead time for the opportunity, and 2) the window of opportunity is

160 comparatively limited as the SSW influence on the troposphere only lasts for about half to two-

161 thirds of a season. Therefore the potential enhancement of forecast skill associated with SSWs is

162 likely to be very limited in standard seasonal forecasts which are generally issued once a month.

163 In an attempt to exploit this source of predictability stemming from the stratosphere, seasonal

164 forecast centers could issue special forecasts once a SSW has been identified in observations.

165 This would require additional computational resources as forecast simulations initialized at non-

166 standard dates would have to be performed. The results presented here suggest that such

167 additional computational effort would be well justified, as the special forecasts are likely to

168 feature enhanced forecast skill with potentially widespread socio-economic benefits. 
171 Observational dataset and model forecasts

172 The 1970-1988 data from ERA-40 (ref. 18) and the 1989-2009 data from ERA-Interim ${ }^{19}$ are 173 merged to provide an observational dataset that is used to initialize and verify the model. To 174 identify Stratospheric Sudden Warmings (SSWs), we apply a criterion based on the Northern 175 Annular Mode (NAM) index instead of the standard WMO criterion which is based on the zonal176 mean zonal wind at $10 \mathrm{hPa}$ and $60^{\circ} \mathrm{N}$, as the NAM index has been shown to better gauge

177 stratosphere-troposphere coupling than zonal-mean zonal wind ${ }^{20}$. A SSW is defined to occur 178 when the NAM index calculated from year-round daily zonal-mean geopotential height 179 following ref. 20 first drops below -2.5 at $30 \mathrm{hPa}$. For winters with multiple SSWs, we only 180 consider the warming with the largest amplitude. Following this procedure 20 warming cases are 181 found between November 1970 and March 2009.

183 The dynamical seasonal forecast system is based on the Canadian Middle Atmosphere Model $184(\mathrm{CMAM})^{14}$, which has 71 vertical levels from the surface up to about $100 \mathrm{~km}$ at T63 horizontal 185 resolution. To assess the forecast skill following SSWs we performed 10-member ensemble 186 model forecasts initialized at the $20 \mathrm{SSW}$ dates identified from the observations. The 10 initial 187 states for each SSW are obtained as follows. Ten model runs are started from 10 slightly 188 different atmospheric states on January 1, 1970. In these 'assimilation' runs, the spatial scales of 189 the vorticity, divergence and temperature that can be represented by spectral truncation T21 are 190 relaxed towards the time-evolving reanalyses between 1970 and 2009. The relaxation time is 24 191 hours, which is selected such that the simulated state closely follows the observed one, and the 
192 resulting RMS spread between ensemble members roughly matches the RMS spread between the 193 different reanalysis data sets. The initial atmospheric and land conditions used for the model

194 forecasts at the onset date of the observed SSWs are obtained from these 10 assimilation runs.

195 The initial sea surface temperature (SST) and sea-ice fields are taken from the HadISST

196 dataset $^{21}$. Instead of persisting the SST anomaly that occurs at initialization time for the duration

197 of the model forecast, which is common for operational two-tier seasonal forecasts, we linearly

198 relax the SST anomaly towards climatology in the first 2 weeks of the forecasts. We apply this

199 procedure to exclude predictability that may arise from SSTs, thus isolating the predictability

200 that stems directly from atmospheric perturbations (i.e., SSWs) alone.

201

202 To assess if the skill for the forecasts initialized during SSWs is significantly larger than a 203 typical, unconditional forecast, we performed a control set of forecasts initialized at the same

204 calendar dates as the SSWs, but in the year preceding and the year following the SSWs. For the 205 warming that occurred in the 1970-1971 (2008-2009) winter, the control forecast in only the 206 following (previous) winter is performed, as no initial conditions were available for the 19692071970 (2009-2010) winters. This results in 38 control forecasts, which are compared to the 20 208 SSW forecasts.

210 In order to calculate anomalies of meteorological fields in the forecast runs, a reference model 211 climatology must be defined. For this purpose, we performed 10-member ensemble model 212 simulations for the period 1970-2009 with prescribed HadISST SST and sea-ice fields, referred 213 to as AMIP runs. Anomalies of sea level pressure (SLP), Surface Temperature (ST) and 214 Precipitation (PCP) in the model forecasts are calculated relative to the corresponding ensemble 
215 mean climatologies in these AMIP runs. The daily NAM index in the model forecasts is obtained

216 by projecting zonal mean geopotential height anomalies relative to the corresponding AMIP

217 climatology onto the observed NAM pattern. We note that during the first $\sim 15$ days of the

218 forecasts the model drifts from observations to the mean behaviour of the AMIP runs (see

219 Supplementary Material). Therefore our analysis focusses on days 16-60 after the SSWs.

221 Forecast skill quantification

222 The forecast skill is quantified by the Correlation Skill Score (CSS) defined as follows. Let $F_{m}$ 223 represent the ensemble mean forecast of a variable (e.g., ST) averaged over a certain period (in 224 this paper, days 16-60) after the forecast initialization date indexed by $m=1, \ldots, M$, and $X_{m}$ 225 represent the corresponding observed value. $M=20(38)$ for the SSW (control) forecasts.

226 The CSS is given by:

$$
C S S=\frac{\operatorname{Cov}_{X, F}}{\sqrt{\operatorname{Var}_{X} \operatorname{Var}_{F}}}
$$

228 where

$$
\begin{aligned}
\operatorname{Cov}_{X, F} & =\frac{1}{M} \sum_{m=1}^{M} X_{m}^{\prime} F_{m}^{\prime} \\
\operatorname{Var}_{X} & =\frac{1}{M} \sum_{m=1}^{M} X_{m}^{\prime 2} \\
\operatorname{Var}_{F} & =\frac{1}{M} \sum_{m=1}^{M} F_{m}^{\prime 2}
\end{aligned}
$$

232 For SLP, ST, and PCP, $X_{m}^{\prime}$ is the observed anomaly relative to the 1970-2009 observed

233 climatology, and $F_{m}^{\prime}$ is the model forecast anomaly relative to the climatology in the AMIP runs.

234 For the NAM index, $X_{m}^{\prime}$ and $F_{m}^{\prime}$ represent the values of the observed and forecast NAM index 235 itself since it is already calculated from anomalies of geopotential height. Statistical significance 
236 of the CSS is determined in a bootstrapping procedure by random sampling with replacement of $237 M$ pairs of $F_{m}^{\prime}$ and $X_{m}^{\prime}$.

238

$239 \underline{\text { References }}$

240 1. Oldenborgh, G.J. van, Balmaseda, M., Ferranti, L., Stockdale, T.N. \& Anderson, D.L.T. 241 Evaluation of atmospheric fields from the ECMWF seasonal forecasts over a 15-year 242 period. J. Clim. 18, 3250-3269 (2005).

243 2. Kirtman, B. \& Pirani, A. WCRP position paper on seasonal prediction. WCRP Informal $244 \quad$ Report 3, (2008).

245

3. NRC, Assessment of Intraseasonal to Interannual Climate Prediction and Predictability

246 (National Academies Press, 2010).

4. Baldwin, M.P. \& Dunkerton, T.J. Stratospheric harbingers of anomalous weather regimes. Science 294, 581-4 (2001).

251

5. Thompson, D.W.J., Baldwin, M.P. \& Wallace, J.M. Stratospheric Connection to Northern Hemisphere Wintertime Weather: Implications for Prediction. J. Clim. 15, $1421-1428$ (2002).

6. Gerber, E.P., Orbe, C. \& Polvani, L.M. Stratospheric influence on the tropospheric circulation revealed by idealized ensemble forecasts. Geophys. Res. Lett. 36, L24801 (2009). 
7. Marshall, A.G. \& Scaife, A.A. Improved predictability of stratospheric sudden warming events in an atmospheric general circulation model with enhanced stratospheric resolution. J. Geophys. Res. 115, D16114 (2010).

8. Baldwin, M.P. et al. Stratospheric memory and skill of extended-range weather forecasts. Science 301, 636-40 (2003).

9. Charlton, A.J., O’Neill, A., Stephenson, D.B., Lahoz, W.A. \& Baldwin, M.P. Can knowledge of the state of the stratosphere be used to improve statistical forecasts of the troposphere? Q. J. R. Meteorol. Soc. 129, 3205-3224 (2003).

10. Christiansen, B. Downward propagation and statistical forecast of the near-surface weather. J. Geophys. Res. 110, D14104 (2005).

11. Siegmund, P. Stratospheric polar cap mean height and temperature as extended-range weather predictors. Mon. Weather Rev. 133, 2436-2448 (2005).

12. Maycock, A.C., Keeley, S.P.E., Charlton-Perez, A.J. \& Doblas-Reyes, F.J. Stratospheric circulation in seasonal forecasting models: implications for seasonal prediction. Clim. Dyn. 36, 309-321 (2011).

13. Mukougawa, H., Hirooka, T. \& Kuroda, Y. Influence of stratospheric circulation on the predictability of the tropospheric Northern Annular Mode. Geophys. Res. Lett. 36, L08814 (2009).

14. Scinocca, J.F., McFarlane, N. A., Lazare, M., Li, J. \& Plummer, D. Technical Note: The CCCma third generation AGCM and its extension into the middle atmosphere. Atmos. Chem. Phys. 8, 7055-7074 (2008). 
15. Thompson, D.W. \& Wallace, J.M. Regional climate impacts of the Northern Hemisphere annular mode. Science 293, 85-9 (2001).

16. Hardiman, S.C., Butchart, N., Hinton, T.J., Osprey, S.M. \& Gray, L.J. The effect of a well resolved stratosphere on surface climate: Differences between CMIP5 simulations with high and low top versions of the Met Office climate model. J. Clim., 25, 7083-7099 (2012).

17. Roff, G., Thompson, D.W.J. \& Hendon, H. Does increasing model stratospheric resolution improve extended-range forecast skill? Geophys. Res. Lett. 38, L05809 (2011).

18. Uppala, S.M. et al. The ERA-40 re-analysis. Q. J. R. Meteorol. Soc. 131, 2961-3012 (2005).

19. Dee, D.P. et al. The ERA-Interim reanalysis: configuration and performance of the data assimilation system. Q. J. R. Meteorol. Soc. 137, 553-597 (2011).

20. Baldwin, M.P. \& Thompson, D.W.J. A critical comparison of stratosphere-troposphere coupling indices. Q. J. R. Meteorol. Soc. 135, 1661-1672 (2009).

21. Rayner, N. A. et al. Global analyses of sea surface temperature, sea ice, and night marine air temperature since the late nineteenth century. J. Geophys. Res. 108, (D14), 4407 (2003). 
296 Figure 1 | Surface climate response to SSWs. a-d, Mean anomaly averaged over days 16-60

297 after all SSWs of sea level pressure (contours), surface temperature (shading in a and b) and

298 precipitation (shading in $\mathbf{c}$ and $\mathbf{d}$ ) for the observations (a and $\mathbf{c}$ ) and the model forecasts (b and

299 d). Contour interval for sea level pressure is $1 \mathrm{hPa}(\ldots,-1.5,-0.5,0.5, \ldots)$, and solid (dashed)

300 contours denote positive (negative) values. Black dots represent statistical significance at the

$30190 \%$ confidence level (determined by bootstrapping) of the shaded quantities. Observed

302 (modeled) SLP anomalies are generally significant at the 90\% level where the mean anomaly

303 exceeds $\sim 1.5(0.5) \mathrm{hPa}$.

Figure 2 | Observed versus forecast 1000 hPa NAM index. a-b, Scatter plot of the observed versus forecast NAM index at $1000 \mathrm{hPa}$ averaged over 16-60 days following the $20 \mathrm{SSWs}$ (a) and the 38 control dates (b). The vertical dashed line and corresponding black dot represent the average observed value, and the horizontal error bar and corresponding gray shading its $95 \%$ confidence interval (as determined by bootstrapping). The horizontal dashed line and corresponding black dot represent the average forecast value, and the vertical error bar and

311 corresponding gray shading its $95 \%$ confidence interval. 
315 Figure 3 | Vertical profile of the mean NAM and of the CSS of the NAM. a-b The mean

316 NAM index averaged over 16-60 days after all SSWs (red) and the control dates (blue) as a

317 function of height for the observations (thick line) and the model forecasts (thin line) (a). The

318 error bars represent the $95 \%$ confidence interval for the model forecast. The forecast skill as

319 quantified by the CSS as a function of height (b). The difference between the SSW and control

320 CSS is statistically significant at the $95 \%$ level where the error bars do not overlap.

321

322

Figure 4 | The CSS of various variables. a-d, The CSS of the NAM at 100 and $1000 \mathrm{hPa}$ (a),

323 NAO index (b), surface temperature (ST) over Northern Russia and Eastern Canada (indicated

324 by the blue boxes in Figs. 1a and 1b) (c), precipitation (PCP) difference between the high latitude

325 and mid-latitude Northern Atlantic (indicated by the blue boxes in Figs. 1c and 1d) (d), and the

326 CSS averaged over $20-90^{\circ} \mathrm{N}$ for SLP (b), ST (land only) (c) and PCP (d). Red (blue) bars

327 represent the SSW (control) forecasts for a forecast range of 16-60 days. The thin lines represent

328 the $95 \%$ confidence interval. P-values for the difference between the SSW and control CSS are

329 given. This difference is statistically significant at the $95 \%$ level when the thick brown lines do

330 not overlap.

331

332

333

334

335 
336 Correspondence

337 Correspondence and requests for materials should be addressed to M.S. (email:

338 sigmond@atmosp.physics.utoronto.ca)

339 Acknowledgments

340 Michael Sigmond gratefully acknowledges funding by Environment Canada through a Grants

341 and Contributions Agreement with the University of Toronto. We thank Bill Merryfield, John

342 Fyfe and Nathan Gillett for their helpful comments.

343 Author contributions

344 M.S., J.F.S. and V.V.K. designed the experiments. All authors interpreted the results and

345 contributed to writing the paper.

$346 \quad \underline{\text { Additional Information }}$

347 Supplementary information accompanies this paper on www.nature.com/naturegeoscience.

$348 \quad$ Competing financial interests

349 The authors declare no competing financial interests.

350

351

352 


\section{K}


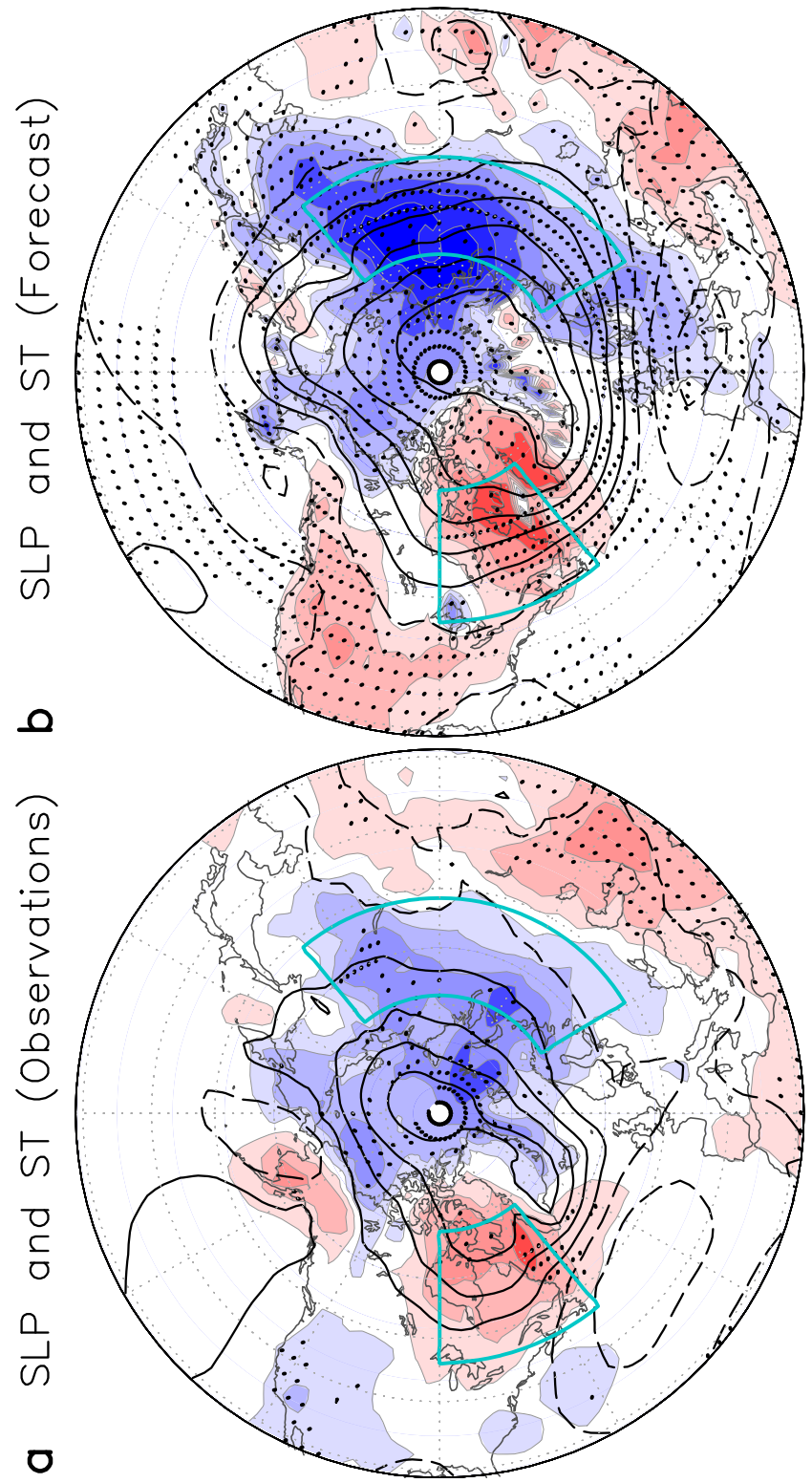

๓



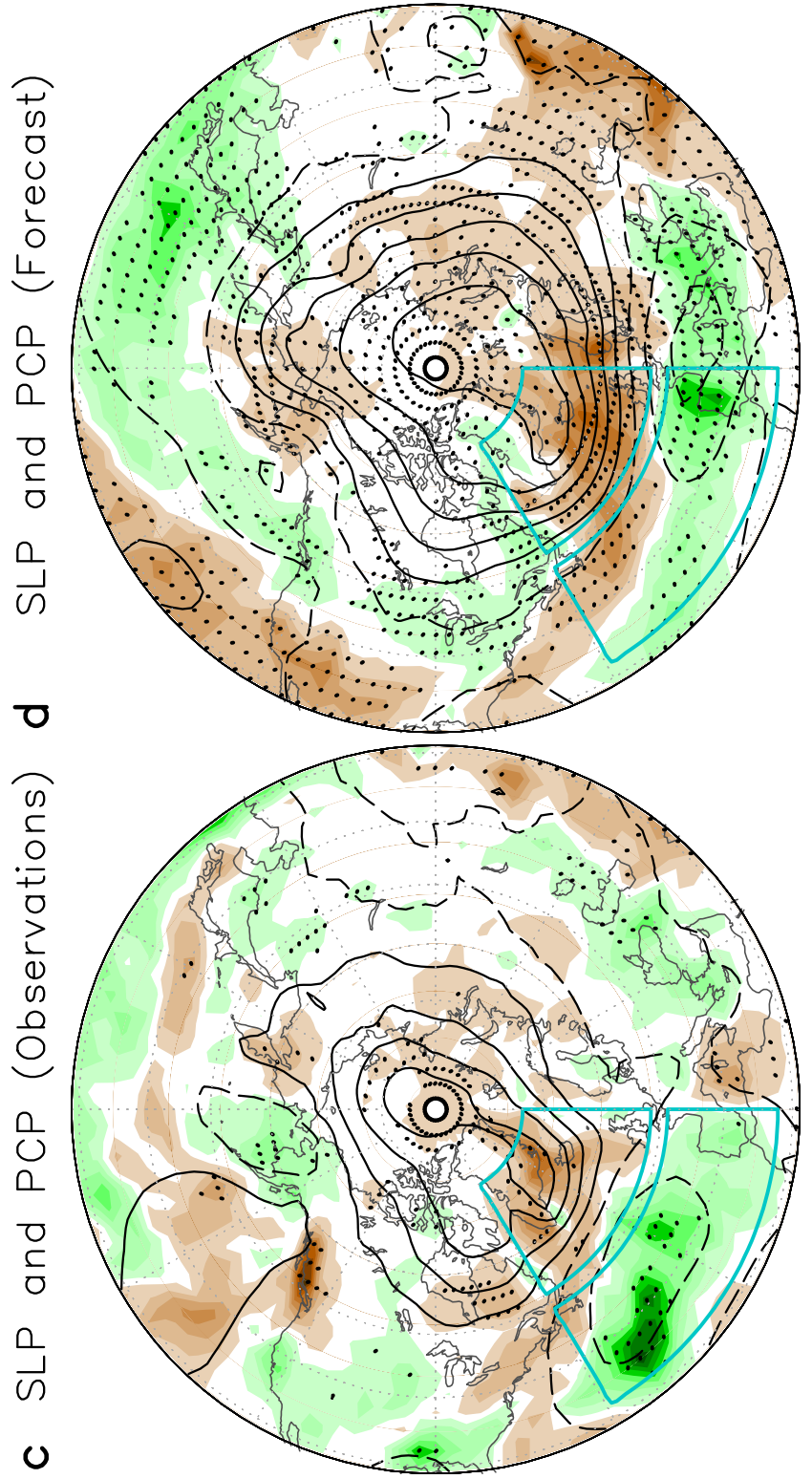




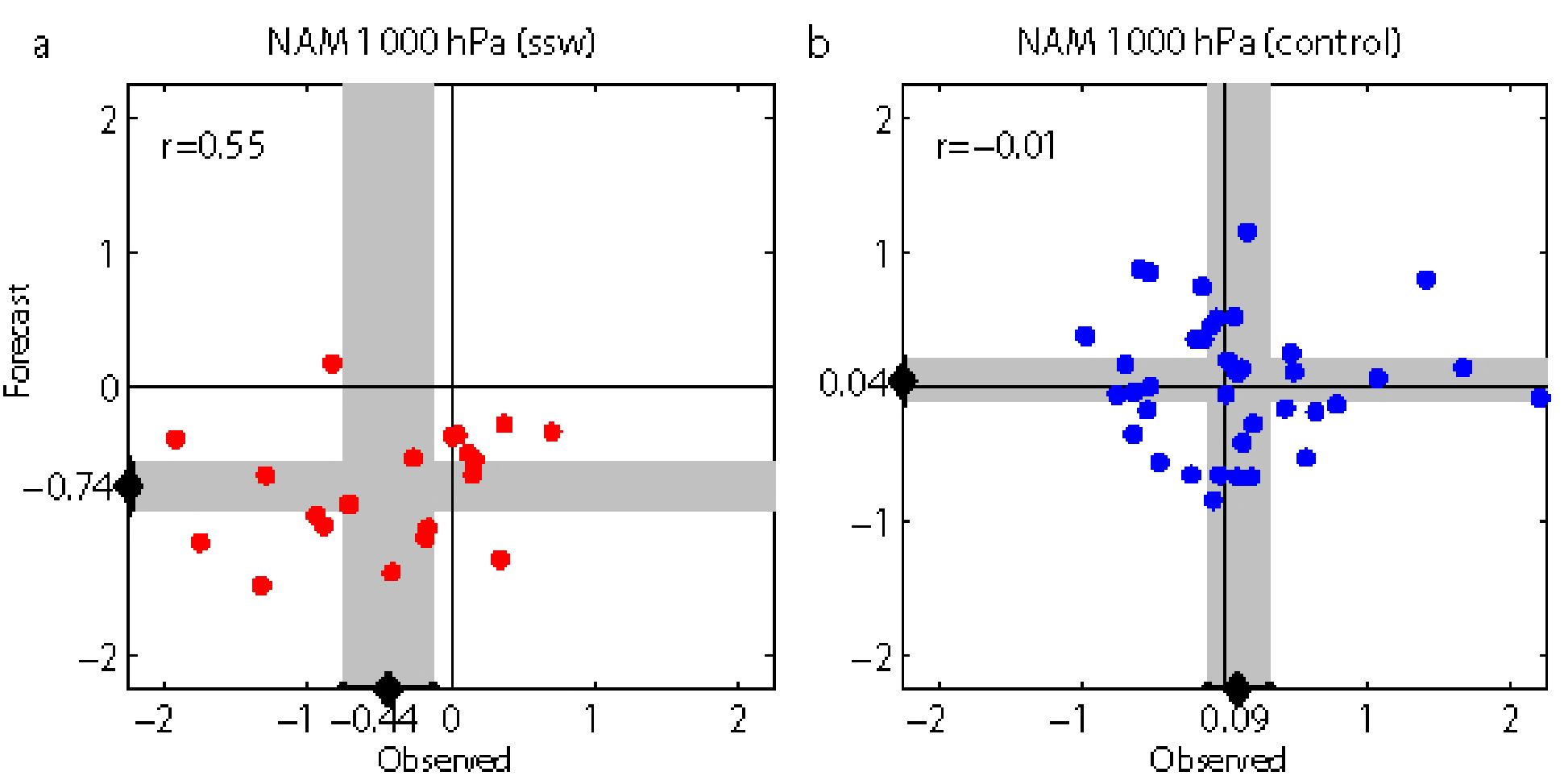




\section{a NAMindex}

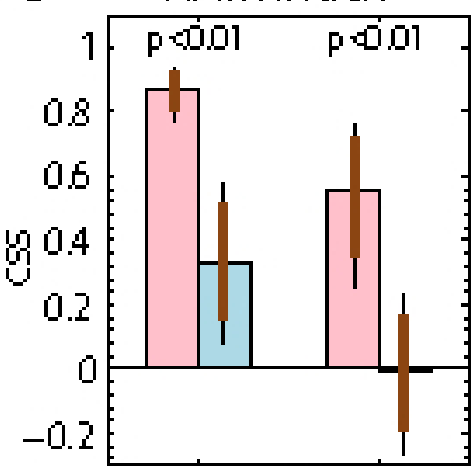

$100 \mathrm{hPa} \quad 1000 \mathrm{hPa}$ b

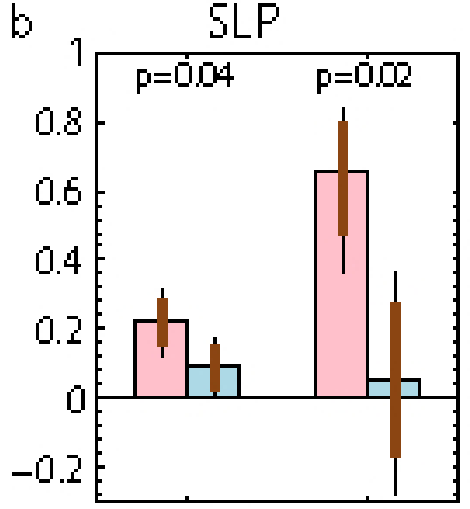

$20-90 \mathrm{~N}$

NAO c Surf. Temperature

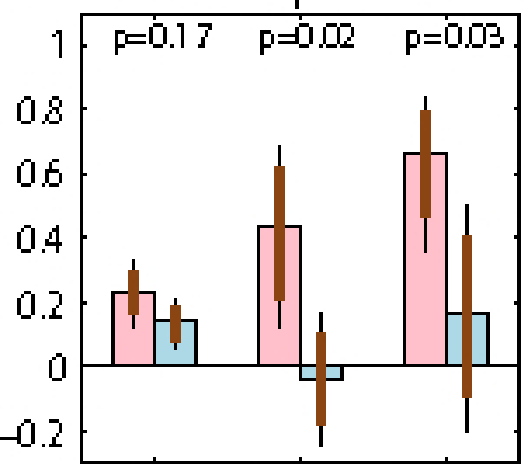

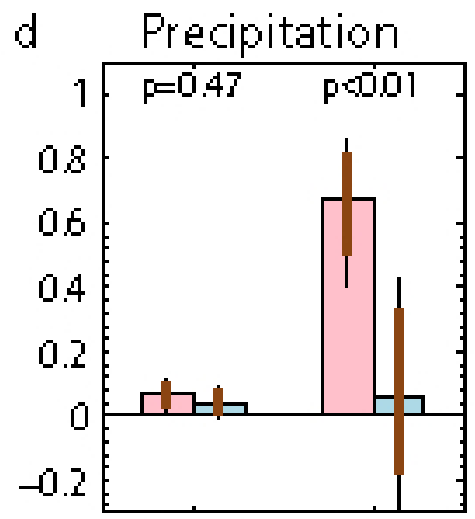

$20-90 \mathrm{~N}$

Atlan 